2016-09-01

Hybrid Wave and Offshore Wind Farms: a Comparative Case Study of

Co-located Layouts

\title{
Astariz, S
}

http://hdl.handle.net/10026.1/8738

International Journal of Marine Energy

All content in PEARL is protected by copyright law. Author manuscripts are made available in accordance with publisher policies. Please cite only the published version using the details provided on the item record or document. In the absence of an open licence (e.g. Creative Commons), permissions for further reuse of content should be sought from the publisher or author. 
1 "This is the author's accepted manuscript. The final published version of this work (the version of record) is published by Elsevier B.V. in International Journal of Marine Energy September 2017 available at: http://dx.doi.org/10.1016/j.ijome.2016.04.016. This work is made available online in accordance with the publisher's policies. Please refer to any applicable terms of use of the publisher."

Hybrid Wave and Offshore Wind Farms: a Comparative Case Study of Co-located Layouts

\author{
S. Astariz ${ }^{\# 1}$, C. Perez-Collazo ${ }^{* 2}$, J. Abanades ${ }^{* 3}$, G. Iglesias ${ }^{* 4}$ \\ ${ }^{\#}$ EPS, Hydraulic Engineering, University of Santiago de Compostela, Spain \\ ${ }^{1}$ sharay.astariz@usc.es \\ ${ }^{*}$ School of Marine Science and Engineering, Plymouth University, Plymouth, UK \\ 2carlos.perezcollazo@plymouth.ac.uk \\ 3javier.abanadestercero@plymouth.ac.uk \\ 4gregorio.iglesias@plymouth.ac.uk
}

\title{
Abstract
}

Marine energy is one of the most promising alternatives to fossil fuels due to the enormous energy resource available. However, it is often considered uneconomical and difficult. Co-located offshore wind

turbines and wave energy converters have emerged as a solution to increase the competitiveness of marine energy. Among the benefits of co-located farms, this work focuses on the shadow effect, i.e. the reduction

24 in wave height in the inner part of the farm, which can lead to significant savings in operation and

maintenance (O\&M) costs thanks to the augmented weather windows for accessing the wind turbines. The aim of this study is to quantify the wave height reduction achieved within a co-located wave-wind farm.

Different locations and a large number of layouts are analysed in order to define the optimum disposition.

28 Keywords: Wave energy; Wind energy; Co-located wind-wave farm; Weather windows for O\&M;

29 Shadow effect; Wave height. 
33 If wave energy is to become a viable alternative to fossil fuels, its competitiveness must be enhanced.

34 Combining this promising marine renewable with a more consolidated renewable like offshore wind 35 energy is a solution of great interest [1]. According to the degree of connectivity between the offshore 36 wind turbines and Wave Energy Converters (WECs) combined wave-wind systems can be classified into:

37 co-located, hybrid and islands systems [2]. According to the current state of development of both 38 technologies, the co-location of WECs into a conventional offshore wind farm is regarded as the best 39 option [2], which combines an offshore wind farm and a WEC array with independent foundation systems 40 but sharing: the same marine area, grid connection, O\&M equipment, etc.

41 There are many synergies between both renewables [3], such as the more sustainable use of the marine 42 resource, the reduction in the intermittency inherent to renewables or the opportunity to reduce costs by 43 sharing some of the most expensive elements of an offshore project. In addition to these powerful reasons 44 there are a number of technology synergies between wave and wind systems which make their 45 combination even more attractive, and this paper focuses on one of them: the so-called shadow effect, i.e. 46 the reduction of the significant wave height in the inner part of the farm. The operational limit of 47 workboats (the most cost-effective access system for maintenance tasks) is a significant wave height of 1.5 $48 \mathrm{~m}$ [4]; when this threshold is exceeded delays in maintenance and repairs ensue, increasing downtime 49 with the associated costs. Thus, while modern onshore wind turbines present accessibility levels of 97\% 50 [5], this level can be significantly reduced in offshore installations .

51 On this basis, the aim of this study is to analyse the wave height reduction achieved by deploying co52 located WECs and the influence of the layout in the results. This purpose is carried out through various 53 cases studies. First, a number of hypothetical co-located farms are analysed in the Wave Hub area. Second, 54 a real wind farm, Alpha Ventus, is considered in order to obtain more realistic conclusions. Finally, the 
55 study extends to three other wind farms currently in operation (Bard 1, Horns Rev 1 and Lincs) to compare

56 the results obtained for each site and draw general conclusions about the benefit of co-located farms and

57 the optimum layouts. A state-of-the-art, third generation wave propagation model (SWAN) implemented

58 on a high-resolution computational grid is applied and real sea conditions are considered.

60 2. Methodology

61 2.1. Preliminary Case Study

62 This case study was carried out for a hypothetical wind farm at the Wave Hub site, an offshore renewable

63 energy (ORE) test centre $20 \mathrm{~km}$ to the northwest of St Ives Bay, in SW England (Figure 1).

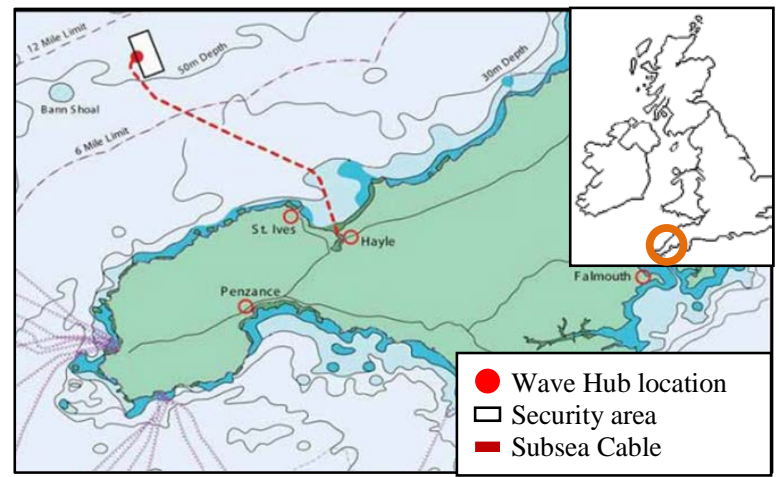

67 The water depth at the test site ranges between 40 and $60 \mathrm{~m}$ [7]. As regards the sea climate, three wave

68 conditions were defined (Table 1) on the basis of the most recent available data [8].

69 Table 1. Case Study (CS): $H_{s}=$ significant wave height; $T_{p}=$ peak period; $\theta=$ mean wave direction.

\begin{tabular}{llll}
\hline $\mathrm{CS}$ & $H_{s}(\mathrm{~m})$ & $T_{p}(\mathrm{~s})$ & $\theta\left(^{\circ}\right)$ \\
\hline 1 & 1.5 & 7.57 & 270 \\
2 & 2.5 & 8.14 & 270 \\
3 & 3.5 & 9.33 & 270 \\
\hline
\end{tabular}


71 The wind farm layout is based on that of Horns Rev 1, with 80 turbines (Vestas V80-2MW) erected on a

72 grid with 10 rows. The spacing between adjacent turbines and rows is $560 \mathrm{~m}$ [9]. Thus, the proposed wind

73 farm would occupy a total area of approximately $20 \mathrm{~km}^{2}$ with an average water depth of $50 \mathrm{~m}$. The

74 substructure of the wind turbines is jacket-frames of $18 \mathrm{~m} \mathrm{x} 18 \mathrm{~m}$. The wind farm is staggered and

75 orientated taking into account the main wind direction in the area in order to maximise the energy output.

76 Having defined the wind farm layout, a Peripherally Distributed Array (PDA) was selected for the co-

77 location of the WECs. The PDA is a type of co-located system which combines both wind and wave

78 arrays by positioning the WECs at the periphery of the offshore wind farm.

79 The WEC used in this case study, and in the following cases, is WaveCat: a floating offshore WEC whose 80 principle of operation is wave overtopping, and with a length overall of $90 \mathrm{~m}$. The minimum distance 81 between devices is $2.2 D$, where $D=90 \mathrm{~m}$ is the distance between the twin bows of a single WaveCat 82 WEC $[10,11]$.

8314 wave farm configurations were proposed: 3 basic layouts (named A, B, C) with different spacing 84 between devices: configuration A, with a spacing between WECs equal to that between turbines, 560 m; 85 configuration B, with a smaller spacing, 345 m; and configuration C, with the minimum spacing allowed, $86198 \mathrm{~m}$. For each of these basic configurations, different layouts were considered (Figure 2): (i) two rows of 87 devices along the west side of the wind farm; (ii) two rows along the west side plus two additional rows of 88 devices along the north and south sides, at an angle of $45^{\circ}$; (iii) two rows of devices forming an arch; and 89 (iv) two rows of devices along an arch rotated $11^{\circ}$ clockwise. These configurations were used to 90 investigate the influence of the layout on the wave characteristics within the wind farm, and more 91 specifically the influence of the spacing between devices and the addition of new lateral rows of devices to 92 intercept waves from secondary directions (NW and SW), and to ascertain whether an arch layout can 93 achieve a similar wave height reduction to an angular layout with fewer WECs. 


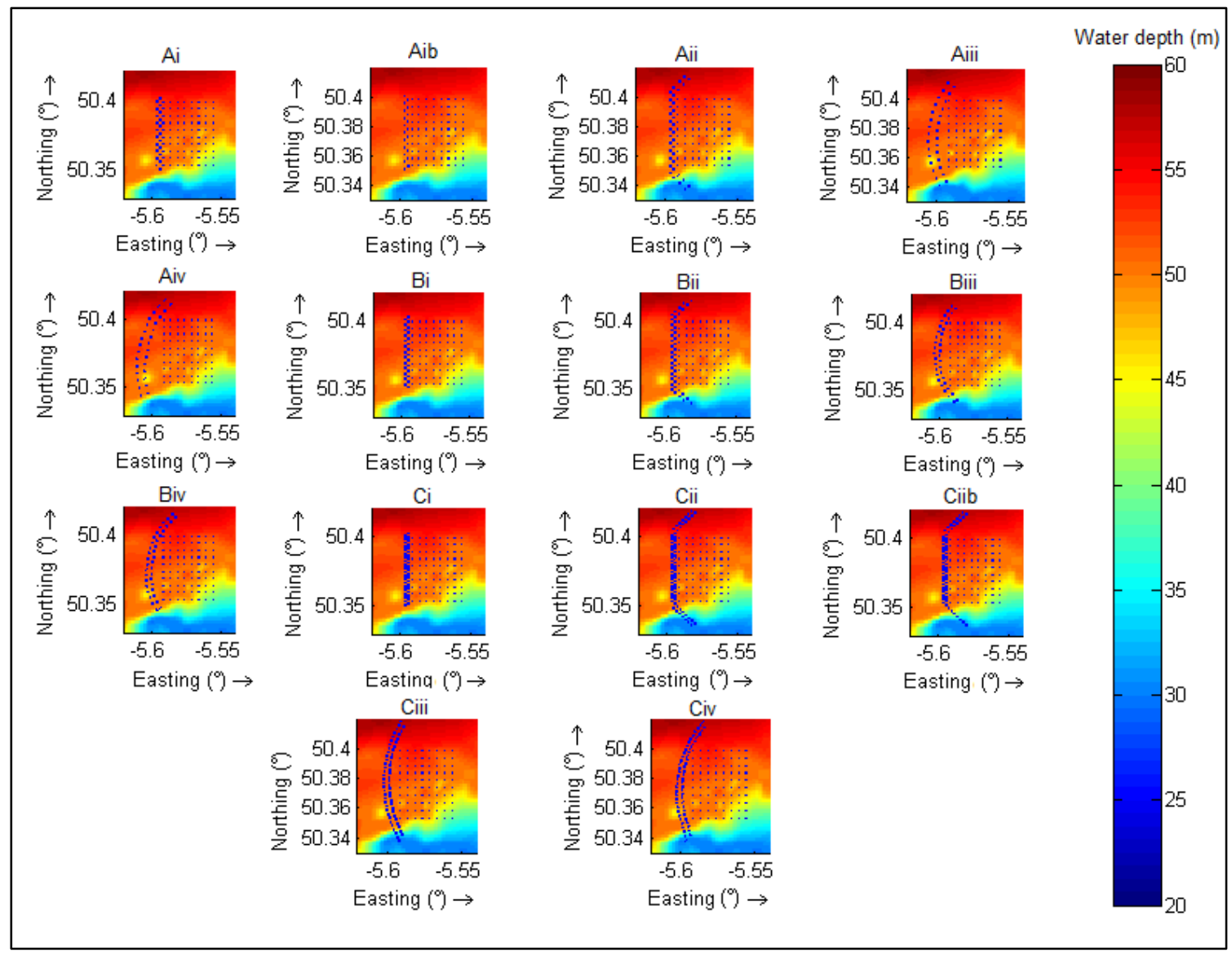

95 Figure 2. Co-located farms at the Wave Hub site: configurations $A_{i}$ to $C_{i v}$.

\subsection{Realistic Case Study}

98 Next, the shadow effect provided by co-located WECs added to an existing wind farm, Alpha Ventus, was 99 investigated using one year's worth of buoy data (from January 2013 to December 2013) from the FINO1 100 research platform, only $400 \mathrm{~m}$ away from the farm (Figure 3) [12]. This park lies about $45 \mathrm{~km}$ north of the 101 island of Borkum (Germany), in water depths of approx. $30 \mathrm{~m}$ [13]. The Alpha Ventus wind farm is 102 composed by 12 turbines: 6 AREVA turbines with a tripod substructure and 6 Repower 5M turbines with 103 a jacket-frame substructure with a spacing between turbines of around $800 \mathrm{~m}$ [14]. In this case, 15 wind104 wave farms configurations were tested (Table 2, Figure 4) characterised by different spacing between 105 WECs, disposition and number of devices $\left(N_{W E C S}\right)$. 


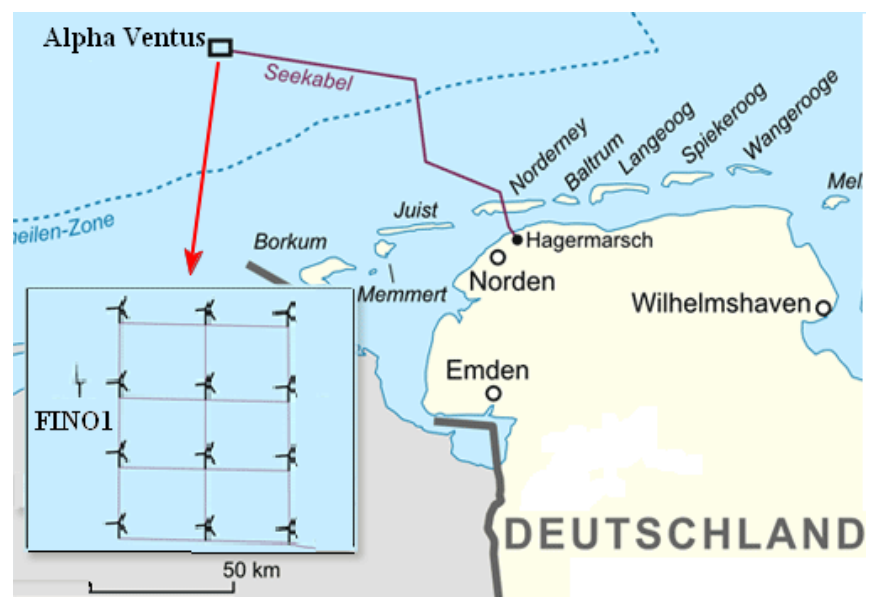

108 Table 2. Characteristics of the WEC layouts

\begin{tabular}{|c|c|c|c|}
\hline Spacing & Name & $N_{W E C}$ & Short description \\
\hline \multirow{3}{*}{$750 \mathrm{~m}$} & $\mathrm{~A}_{\mathrm{i}}$ & 9 & Two rows to the NW. \\
\hline & $\mathrm{A}_{\mathrm{ii}}$ & 12 & Two rows to the NW and two more rows to the $\mathrm{W}$. \\
\hline & $\mathrm{A}_{\mathrm{iii}}$ & 12 & Arch to the NW. \\
\hline \multirow{3}{*}{$450 \mathrm{~m}$} & $\mathrm{~B}_{\mathrm{i}}$ & 12 & Two rows to the NW. \\
\hline & $\mathrm{B}_{\mathrm{ii}}$ & 17 & Two rows to the NW and two more rows to the W. \\
\hline & $\mathrm{B}_{\mathrm{iii}}$ & 17 & Arch to the NW. \\
\hline \multirow{3}{*}{$198 \mathrm{~m}$} & $\mathrm{C}_{\mathrm{i}}$ & 22 & Two rows to the NW \\
\hline & $\mathrm{C}_{\mathrm{ii}}$ & 30 & Two rows to the NW and two more rows to the W. \\
\hline & $\mathrm{C}_{\mathrm{iii}}$ & 28 & Arch to the NW. \\
\hline \multirow{6}{*}{$198 \mathrm{~m}$} & $\mathrm{C}_{\mathrm{ib}}$ & 27 & $\begin{array}{l}\text { Two rows to the NW and one more row to the SW } \\
\text { of the farm constituted by } 5 \text { additional WECs. }\end{array}$ \\
\hline & $\mathrm{C}_{\mathrm{ic}}$ & 31 & $\begin{array}{l}\text { Two rows to the NW and two more rows to the SW } \\
\text { of the farm constituted by } 9 \text { additional WECs. }\end{array}$ \\
\hline & $\mathrm{C}_{\mathrm{iib}}$ & 32 & $\begin{array}{l}\text { Two rows to the NW and two to the W ( } 2 \\
\text { additional WECs). }\end{array}$ \\
\hline & $\mathrm{C}_{\mathrm{iic}}$ & 34 & $\begin{array}{l}\text { Two rows to the NW and two to the W (4 } \\
\text { additional WECs). }\end{array}$ \\
\hline & $\mathrm{C}_{\mathrm{iiib}}$ & 30 & $\begin{array}{l}\text { Arch to the NW } \\
\text { ( } 2 \text { additional WECs). }\end{array}$ \\
\hline & $\mathrm{C}_{\mathrm{iiic}}$ & 32 & Arch to the NW with 4 additional WECs. \\
\hline
\end{tabular}



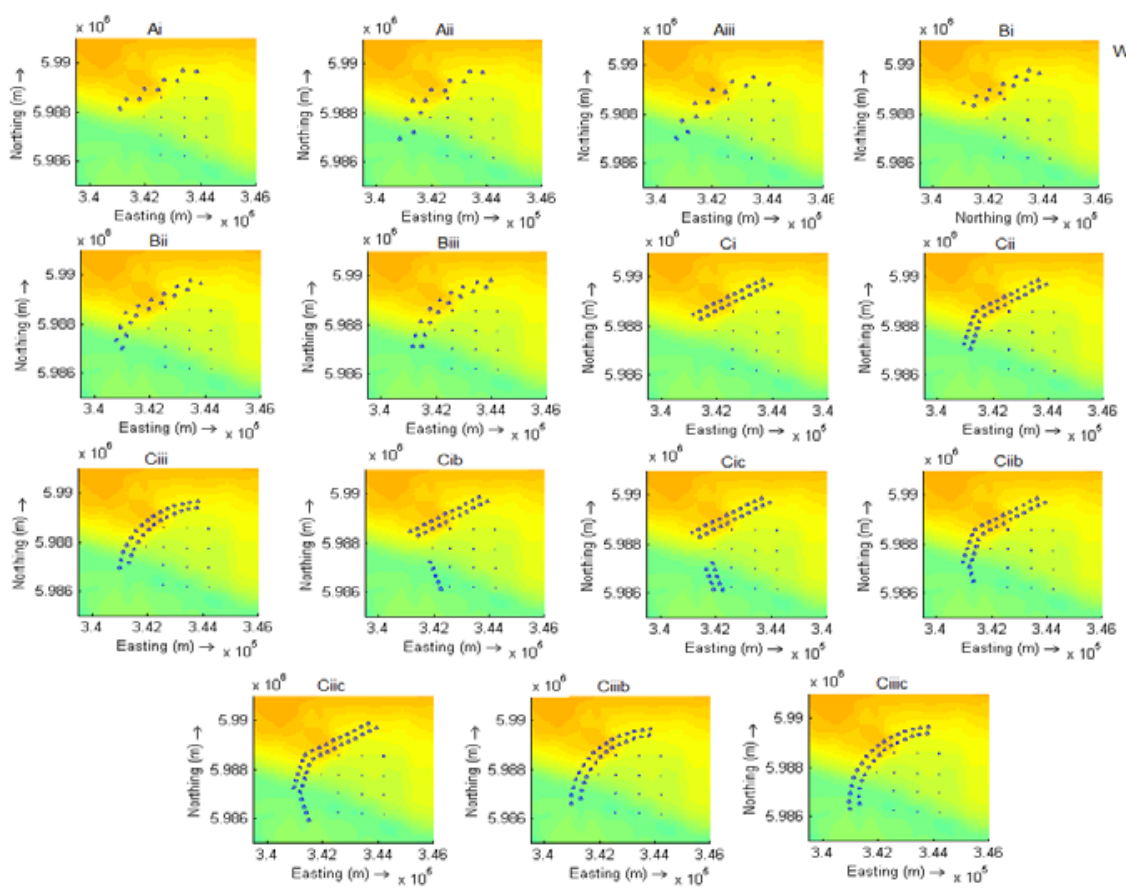

Figure 4. Co-located wave-wind farm layouts in Alpha Ventus (configurations $A_{i}$ to $C_{i i i c}$ ) and water depth (m).

\section{$112 \quad$ 2.3. Comparative Study}

113 The results of the previous study of AlphaVentus were taken as a reference for three further cases,

114 corresponding to as many wind farms currently in operation: Bard 1, Horns Rev 1 and Lincs, whose

115 locations and characteristics are presented in Figure 5 and Table 3, respectively. These four wind farms

116 encompass a wide variety of characteristics on which to establish a comparative analysis.

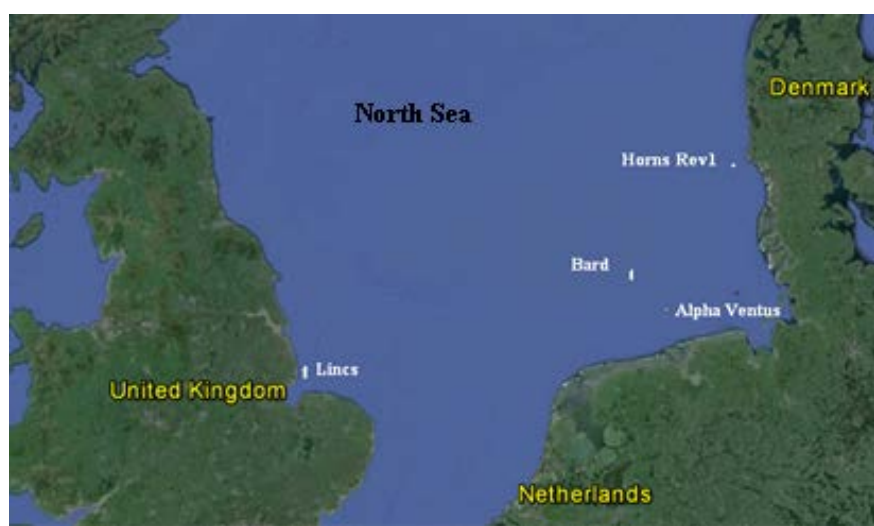

119 Figure 5. Location of the four wind farms used in this study: Alpha Ventus, Bard 1, Horns Rev 1 and Lincs. 
Table 3. Characteristics of the wind farms

\begin{tabular}{llllll}
\hline Wind farm & Depth $(\mathrm{m})$ & $\begin{array}{l}\text { Distance from } \\
\text { shore }(\mathrm{km})\end{array}$ & $\begin{array}{l}\text { Installed } \\
\text { capacity }(\mathrm{MW})\end{array}$ & $\begin{array}{l}\text { Number } \\
\text { turbines }\end{array}$ & Area $\left(\mathrm{km}^{2}\right)$ \\
\hline Alpha Ventus & $33-45$ & 56 & 60 & 12 & 4 \\
Bard 1 & $39-41$ & $90-101$ & 400 & 80 & 59 \\
Horns Rev 1 & $6-14$ & $14-20$ & 160 & 80 & 21 \\
Lincs & $8-16$ & 8 & 270 & 75 & 41 \\
\hline
\end{tabular}

Alpha Ventus and Horns Rev have been characterised previously. For their part, Bard 1 is composed of 80 1265 MW turbines (Bard 5.0) on tripod substructures [15], and Lincs of 75 3.6 MW Siemens turbines on 127 monopiles [16]. In Alpha Ventus and Horns Rev 1 the wind turbines are arranged on a Cartesian grid, 128 whereas in Bard 1 and Lincs they are not organised in clearly defined rows, and the distance between 129 turbines varies in each case. As regards the sea climate, wave buoy measurements were used, and the main 130 wave climate parameters are shown in Table 4: $H_{s}$ is the significant wave height, $T_{m 01}$ the mean wave 131 period, $\theta$ the mean wave direction, $U_{w}$ the most frequent wind speed at $10 \mathrm{~m}$, and $D_{w}$ the corresponding 132 wind direction.

134 Table 4.Wave and wind conditions at the wind farm site.

\begin{tabular}{lccccc}
\hline Wind farm & $H_{s}(\mathrm{~m})$ & $T_{m o 1}(\mathrm{~s})$ & $\theta\left(^{\circ}\right)$ & $U_{w}\left(\mathrm{~ms}^{-1}\right)$ & $D_{w}\left(^{\circ}\right)$ \\
\hline Alpha Ventus & 1.5 & 4.6 & 330 & 10 & $210-240$ \\
Bard 1 & $0.8-1.5$ & 4.0 & 320 & 9.2 & 330 \\
Horns Rev 1 & $0.8-1$ & $4-4.6$ & $230-340$ & 9.7 & $225-315$ \\
Lincs & $0.6-0.7$ & $3.4-4.4$ & $0-15$ & 8.4 & $10-70$ \\
\hline
\end{tabular}

Two co-located WECs layouts (Table 5) were proposed taking into account the wind farm layouts, the wave climate, and the results of previous studies. In the first case (Figure 6), the co-located WECs configuration consists of two main rows of WECs with a spacing of $198 \mathrm{~m}$ orientated towards the prevailing wave direction, and other rows of WECs at an angle of $45^{\circ}$ to face secondary wave directions and thus protect a larger wind farm area. With the second configuration (Figure 7) the aim is to check if 
141 deploying WECs in an arch can lead to a wave height reduction similar to that obtained with an angular

142 layout with fewer WECs.

143

144 Table 5. Total number of co-located WECs and the rate between the total number of WECs and wind 145 turbines $(r)$.

\begin{tabular}{|c|c|c|c|c|}
\hline \multirow{2}{*}{ Wind farm } & \multicolumn{2}{|c|}{ Layout in angle } & \multicolumn{2}{|c|}{ Layout in arch } \\
\hline & Total & $r$ & Total & $r$ \\
\hline Alpha Ventus & 34 & $\begin{array}{c}2.8 \\
3\end{array}$ & 32 & $\begin{array}{c}2.6 \\
7\end{array}$ \\
\hline Bard 1 & 79 & $\begin{array}{c}0.9 \\
9\end{array}$ & 79 & $\begin{array}{c}0.9 \\
9\end{array}$ \\
\hline Horns Rev 1 & 55 & $\begin{array}{c}0.6 \\
9\end{array}$ & 53 & $\begin{array}{c}0.6 \\
6\end{array}$ \\
\hline Lincs & 81 & $\begin{array}{c}1.0 \\
1\end{array}$ & 80 & 1 \\
\hline
\end{tabular}

146
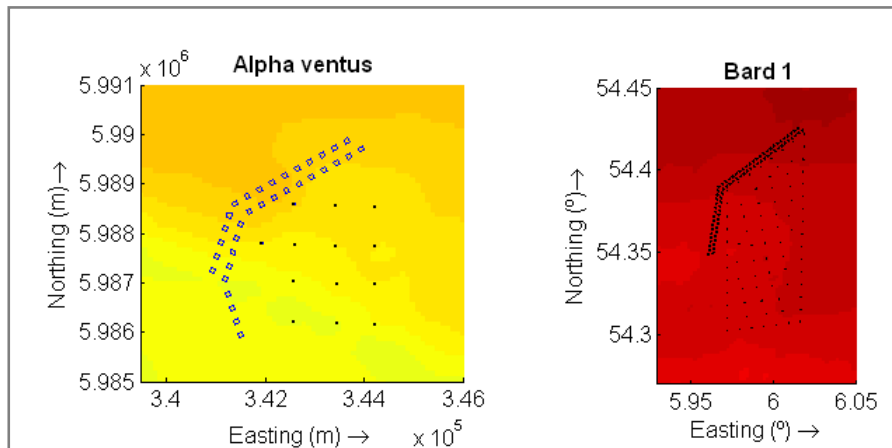

Depth (m)
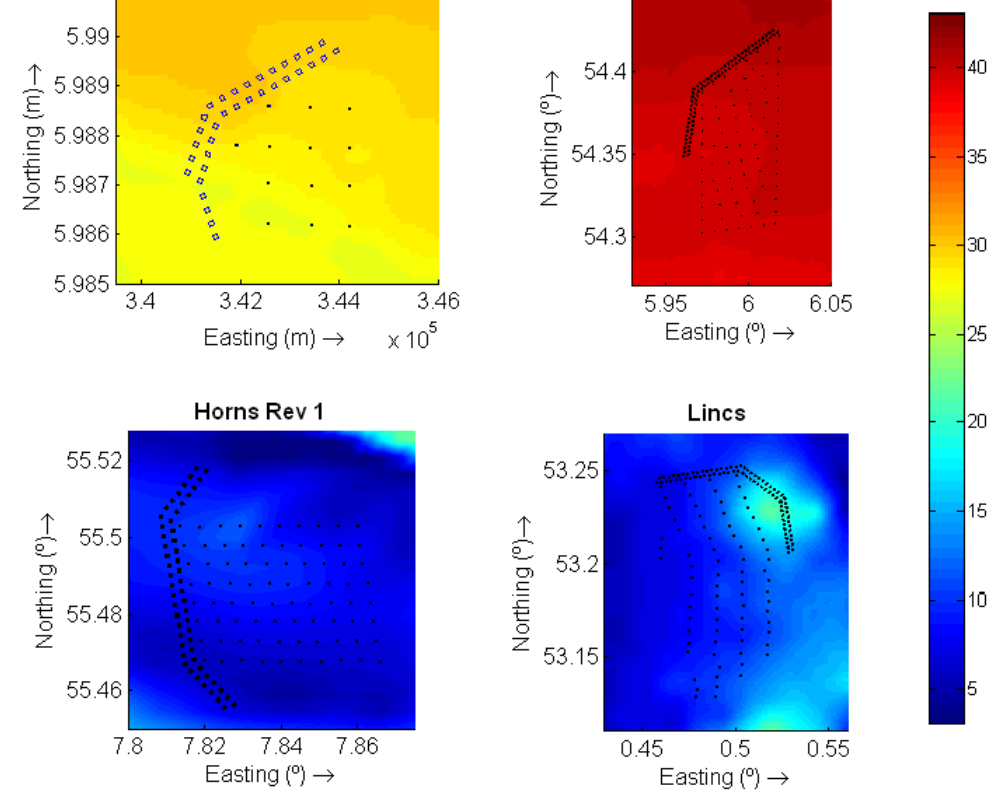

Figure 6. Co-located wind farm layouts with WECs at an angle. 

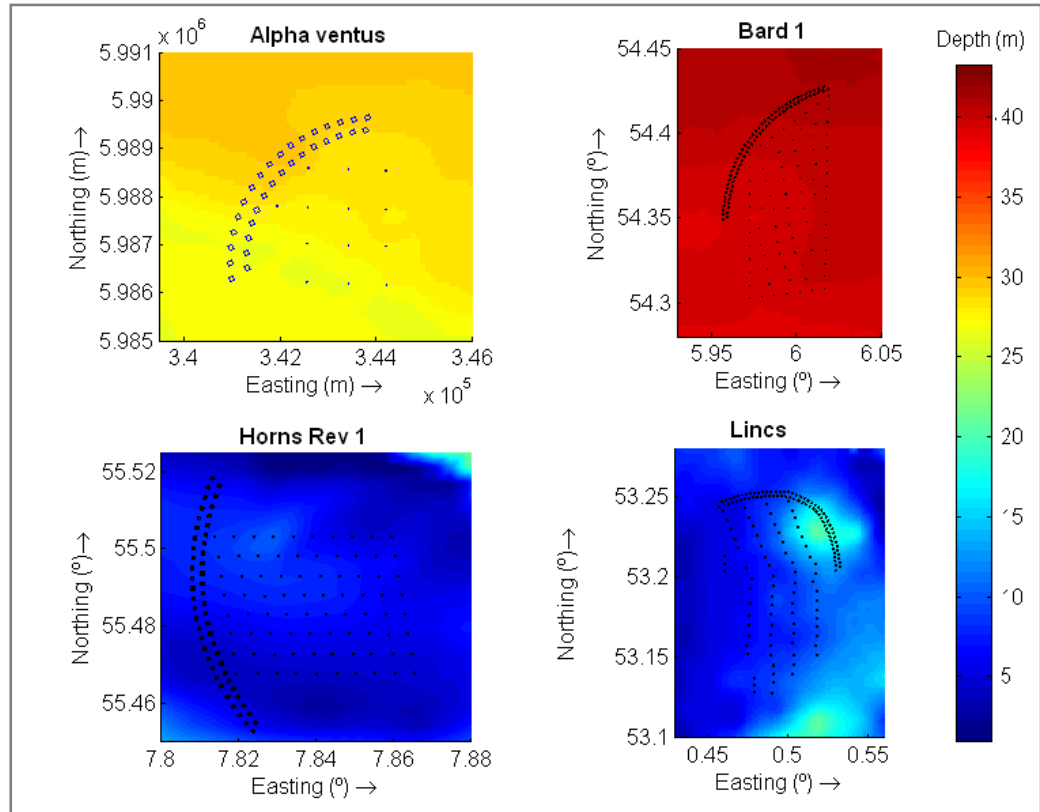

\section{2}

Figure 7. Co-located wind farms layouts with WECs in arch.

\subsection{The Wave Propagation Model}

153 The assessment of the wave height reduction in the wind farm caused by the co-located WECs was carried 154 out using a third-generation numerical wave model, SWAN (Simulating WAves Nearshore), which was 155 successfully used in previous works (e.g. [17-19]) to model the impact of a wave farm on nearshore wave 156 conditions. The evolution of the wave field is described by the action balance equation, Eq. (1), which equates the propagation of wave action density in each dimension balanced by local changes to the wave 158 spectrum:

$$
\frac{\partial}{\partial t} N+\frac{\partial}{\partial x} c_{x} N+\frac{\partial}{\partial y} c_{y} N+\frac{\partial}{\partial \sigma} c_{\sigma} N \frac{\partial}{\partial \theta} c_{\theta} N=\frac{s_{t o t}}{\sigma}
$$
where $t$ is time (s), $c_{x}$ and $c_{y}$ are spatial velocities in the $x$ and $y$ components $\left(\mathrm{ms}^{-1}\right), c_{\theta}$ and $c_{\sigma}$ are rates of change of group velocity which describe the directional $(\theta)$ rate of turning and frequency $(\sigma)$ shifting due to changes in currents and water depth, $\mathrm{N}$ is wave action density spectrum, and $S_{\text {tot }}$ is the energy density source terms which describe local changes to the wave spectrum. 
In this work the model was implemented in the so-called nested mode, with two computational grids

(Table 6) in order to obtain high-resolution results without excessive computational cost. The bathymetric data, from the UK’s data centre Digimap, were interpolated onto this grid.

167 Table 6. Surface area covered by the computational grids and grid size.

\begin{tabular}{lcccc}
\hline \multirow{2}{*}{ Wind farm } & \multicolumn{2}{c}{ Coarse grid } & \multicolumn{2}{c}{ Nested grid } \\
\cline { 2 - 5 } & Area $(\mathrm{km})$ & Resolution $(\mathrm{m})$ & Area $(\mathrm{km})$ & Resolution $(\mathrm{m})$ \\
\hline Alpha & $40 \times 30$ & $100 \times 100$ & $8.5 \times 8.5$ & $17 \times 17$ \\
Ventus & $111 \times 111$ & $222 \times 222$ & $18 \times 22$ & $40 \times 40.4$ \\
Bard 1 & $42 \times 32$ & $70 \times 80$ & $9.35 \times 9$ & $17 \times 20$ \\
Horns Rev1 & $119 \times 111$ & $170 \times 159$ & $14.4 \times 18.2$ & $32 \times 33$ \\
Lincs & & & & \\
\hline
\end{tabular}

The wind turbines were represented in the model by a transmission coefficient, whose value can vary in 170 theory from $0 \%$ (i.e., $100 \%$ of incident wave energy absorbed) to $100 \%$. This technique was used in 171 previous studies to represent single wind turbines [20] or wind farm arrays [21], and arrays of WECs [22].

172 In this study, the transmission coefficient of the offshore wind turbines was calculated by [23]:

$$
\begin{gathered}
c_{t}=4\left(\frac{d}{H_{i}}\right) E\left[-E+\sqrt{E^{2}+\frac{H_{i}}{2 d}}\right] \\
E=\frac{C_{d\left(\frac{b}{D+b}\right)}}{\sqrt{1-\left(\frac{b}{D+b}\right)^{2}}}
\end{gathered}
$$

175 where $d$ is depth (m), $H_{i}$ is incident significant wave height (m), $D$ is the pile diameter $(\mathrm{m}), b$ is the pile 176 spacing (m), and $C_{d}$ is the drag coefficient of the piles (1.0 for a smooth pile).

177 As for the co-located WECs, the WEC used was the WaveCat, and its wave transmission coefficient was implemented into the wave propagation model based on the laboratory tests reported by Fernandez, Iglesias [11].

\subsection{Impact Indicators}

181 To compare the results achieved in the proposed co-located farms a series of impact indicators were 182 defined: (i) the significant wave Height Reduction within the Farm (HRF), (ii) the significant wave Height 
183 Reduction within the $j$-th Area of wind turbines (HRAj), and (iii) the increase in access time for O\&M

$184\left(\triangle T_{O \& M}\right)$. The $H R F$ and $H R A_{j}$ indices provide information about the average wave height reduction within

185 the wind farm and the wave recovery with increasing distance from the WECs, respectively, and were

186 calculated by

$$
\operatorname{HRF}(\%)=\frac{100}{n} \sum_{i=1}^{n} \frac{1}{\left(H_{s, b}\right)_{i}}\left[\left(H_{s, b}\right)_{i}-\left(H_{s, W}\right)_{i}\right]
$$

188 where the index $i$ designates a generic turbine of the wind farm, $n$ is the total number of turbines, $\left(H_{s, b}\right)_{i}$ is 189 the significant height incident on the $i$-th turbine in the baseline scenario (without WECs), and $\left(H_{s, W}\right)_{i}$ is 190 the significant height incident on the $i$-th turbine with co-located WECs.

$$
H R A_{j}(\%)=\frac{100}{m} \sum_{i=1}^{m} \frac{1}{\left(H_{s, b}\right)_{i}}\left[\left(H_{S, b}\right)_{i}-\left(H_{s, W}\right)_{i}\right]
$$

192 where the index $i$ denotes a generic turbine of the $j$-th area of the wind farm, and $m$ is the number of 193 turbines in the $j$-th area. In the case of Alpha Ventus and Horns Rev 1 each $j$-th area corresponds to a 194 vertical row of turbines numbered from east to west, $j=1,2$, 3 in Alpha Ventus and $j=1,2 \ldots 10$ in Horns 195 Rev 1. However, in the other two wind farms, due to the less orderly layout, the division was made into 196 different areas with a similar number of turbines, and numbered according to the mean wave direction 197 (Figure 8). 

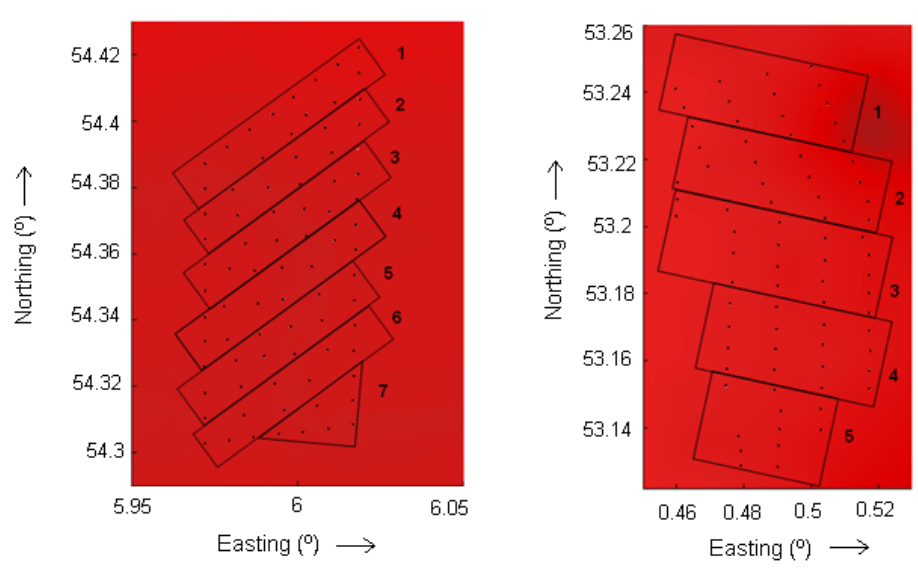

Figure 8. The $j$-th areas into which Bard 1 (left) and Lincs (right) were divided to calculate the $H R A_{j}$ index. The $\Delta T_{O \& M}$ non-dimensional index allows the assessment of the increase in the timeframe accessibility to the wind turbines thanks to the co-located WECs, and can be computed from

$$
\Delta T_{O \& M}(\%)=\frac{T_{W}-T_{b}}{T_{W}} \times 100
$$

where $T_{W}$ and $T_{b}$ are the total number of hours per year when $H_{s}$ within the wind farm is lower or equal to

$1.5 \mathrm{~m}$ with co-located WECs and in the baseline scenario, respectively.

\section{Results and Discussion}

\subsection{Preliminary Study}

209 As regards the wave height reduction (Table 7), a value of $H R F$ between $12 \%\left(\mathrm{~A}_{\mathrm{ib}}\right)$ and $24 \%\left(\mathrm{C}_{\mathrm{i}}\right)$ was 210 obtained for the configurations $\mathrm{X}_{\mathrm{i}}$, with $\mathrm{X}=\mathrm{A}, \mathrm{B}, \mathrm{C}$. In the case of $560 \mathrm{~m}$ as spacing between devices, two 211 situations were analysed $\left(\mathrm{A}_{\mathrm{i}}\right.$ and $\left.\mathrm{A}_{\mathrm{ib}}\right)$ in order to evaluate the difference between aligning the devices of 212 the first or second row with the wind turbines. $H R F$ values were higher in the first case $\left(\mathrm{A}_{\mathrm{i}}\right)$, and therefore 213 this arrangement was retained for all the other layouts. 
Table 7. HRF (\%) values for case studies CS1, CS2 and CS3 and configurations $\mathrm{A}_{\mathrm{i}}$ to $\mathrm{C}_{\mathrm{iv}}$.

\begin{tabular}{cccc}
\hline Configuration & CS1 & CS2 & CS3 \\
\hline $\mathrm{A}_{\mathrm{i}}$ & 13 & 13 & 13 \\
$\mathrm{~A}_{\mathrm{ib}}$ & 12 & 12 & 12 \\
$\mathrm{~B}_{\mathrm{i}}$ & 16 & 16 & 16 \\
$\mathrm{C}_{\mathrm{i}}$ & 24 & 24 & 24 \\
$\mathrm{~A}_{\mathrm{ii}}$ & 14 & 14 & 14 \\
$\mathrm{~B}_{\mathrm{ii}}$ & 18 & 18 & 18 \\
$\mathrm{C}_{\mathrm{ii}}$ & 26 & 26 & 26 \\
$\mathrm{C}_{\mathrm{iib}}$ & 25 & 25 & 25 \\
$\mathrm{~A}_{\mathrm{iii}}$ & 11 & 11 & 11 \\
$\mathrm{~B}_{\mathrm{iii}}$ & 17 & 17 & 17 \\
$\mathrm{C}_{\mathrm{iii}}$ & 25 & 25 & 25 \\
$\mathrm{~A}_{\mathrm{iv}}$ & 15 & 15 & 15 \\
$\mathrm{~B}_{\mathrm{iv}}$ & 17 & 17 & 17 \\
$\mathrm{C}_{\mathrm{iv}}$ & 27 & 27 & 28 \\
\hline
\end{tabular}

218 The configurations with two more rows of 7 WECs at an angle of $45^{\circ}\left(\mathrm{X}_{\mathrm{ii}}\right.$, with $\left.\mathrm{X}=\mathrm{A}, \mathrm{B}, \mathrm{C}\right)$ led to higher

$219 H R F$ values than the corresponding Xi configurations, increasing the wave reduction by 6-8\%. Indeed, a

220 barrier of WECs to the northwest and southwest of the farm is essential to intercepting the waves from

221 these directions, and to retard wave regeneration within the farm. As regards the layout with the smallest

222 spacing, $198 \mathrm{~m}\left(\mathrm{C}_{\mathrm{ii}}\right)$, the average $H R F$ value was $26 \%$ for $\mathrm{C}_{\mathrm{ii}}$ and $25 \% \mathrm{C}_{\mathrm{iib}}$, indicating that that the second

223 row to the south does not contribute to the wave height reduction, and therefore is not worth being

224 included.

225 In the $\mathrm{X}_{\mathrm{iii}}$ configurations, with an arched WEC layout, $H R F$ values were a little lower than in the $\mathrm{X}_{\mathrm{ii}}$

226 configurations. The explanation may lie in the reduction of the number of converters and in the fact that

227 NW waves are not well intercepted. However, when the arch was rotated ( $\mathrm{X}_{\mathrm{iv}}$ configurations) the highest

228 value of $H R F$ was obtained - the $C_{\text {iv }}$ configuration, with an average value of $H R F$ of $27 \%$. This could be

229 caused by the refraction of the waves in the vicinity of the wind farm, veering from west to northwest.

230 In brief, the greatest wave height reduction was obtained for the minimum spacing between devices $-H R F$

231 values are around50\% greater than those achieved in the configurations with the maximum spacing. 
232 Moreover, deploying WECs not only along the W side of the farm but also along its SW and NW sides

233 reduces the wave height by more than 13\%. Finally, arched configurations require fewer WECs for

234 equivalent levels of wave height reduction.

\section{3.2. Realistic Case Study}

236 First, the results obtained from the nearshore wave propagation model were successfully validated with the 237 wave data from the FINO1 platform, as demonstrated by the values obtained for the coefficient of 238 determination $\left(R^{2}\right)$ and the Root Main Square Error $(R M S E): R^{2}=0.95$ and $R M S E=0.36 \mathrm{~m}$.

239 Having validated the numerical model, it was used to analyse the shadow effect caused by the 9 basic

240 wind-wave farm layouts $\left(\mathrm{A}_{\mathrm{i}}\right.$ to $\left.\mathrm{C}_{\mathrm{iii}}\right)$. First, the prevailing sea climate was considered in these simulations 241 Case Study 1 (CS1): $H_{s}=1.5 \mathrm{~m}, T_{p}=6.5 \mathrm{~m}$ and $\theta=330^{\circ}-$ to draw initial conclusions about the 242 configuration that would maximise the weather windows for O\&M. Second, and to cover the secondary 243 wave direction, the same simulations were carried out but considering southwestly waves $-\mathrm{CS} 2: H_{s}=1.5$ $244 \mathrm{~m}, T_{p}=6.5 \mathrm{~m}$ and $\theta=250^{\circ}$.

245 The results are shown graphically in Figure 9 and 10, and numerically in Table 8. Comparing the different 246 layouts, there was a small difference between configurations $\mathrm{X}_{\mathrm{ii}}$ and $\mathrm{X}_{\mathrm{iii}}$, whereas poorer results were 247 obtained for the configurations $\mathrm{X}_{\mathrm{i}}$. Regarding the influence of the spacing between devices, the 248 configurations $C_{x}$ led to the largest reductions. Based on these assessments and with the objective of a 249 better protection from $\mathrm{W}$ and $\mathrm{SW}$ waves, 6 new configurations $\left(\mathrm{C}_{\mathrm{ib}, \mathrm{c}}, \mathrm{C}_{\mathrm{iib,c}}\right.$ and $\left.\mathrm{C}_{\mathrm{iiib,c}}\right)$ were analysed, 250 consisting in variants of $C_{x}$ layouts. 

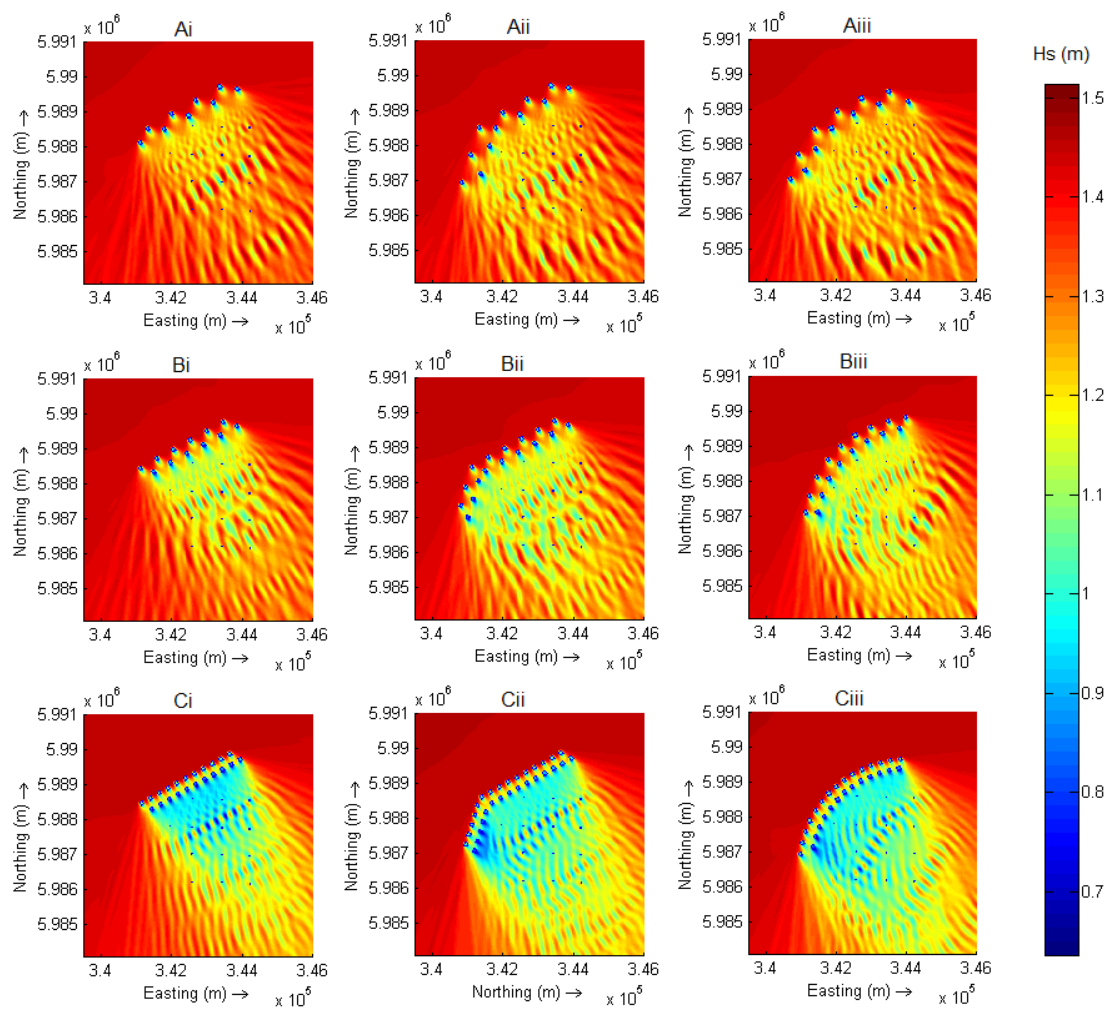

Figure 9. Wave height reduction within the wind farm $(H R F)$ for $H_{s}=1.5 \mathrm{~m}, T_{p}=6.5 \mathrm{~m}$ and $\theta=330^{\circ}$ and configurations $\mathrm{A}_{\mathrm{i}}$ to $\mathrm{C}_{\mathrm{iii}}$.
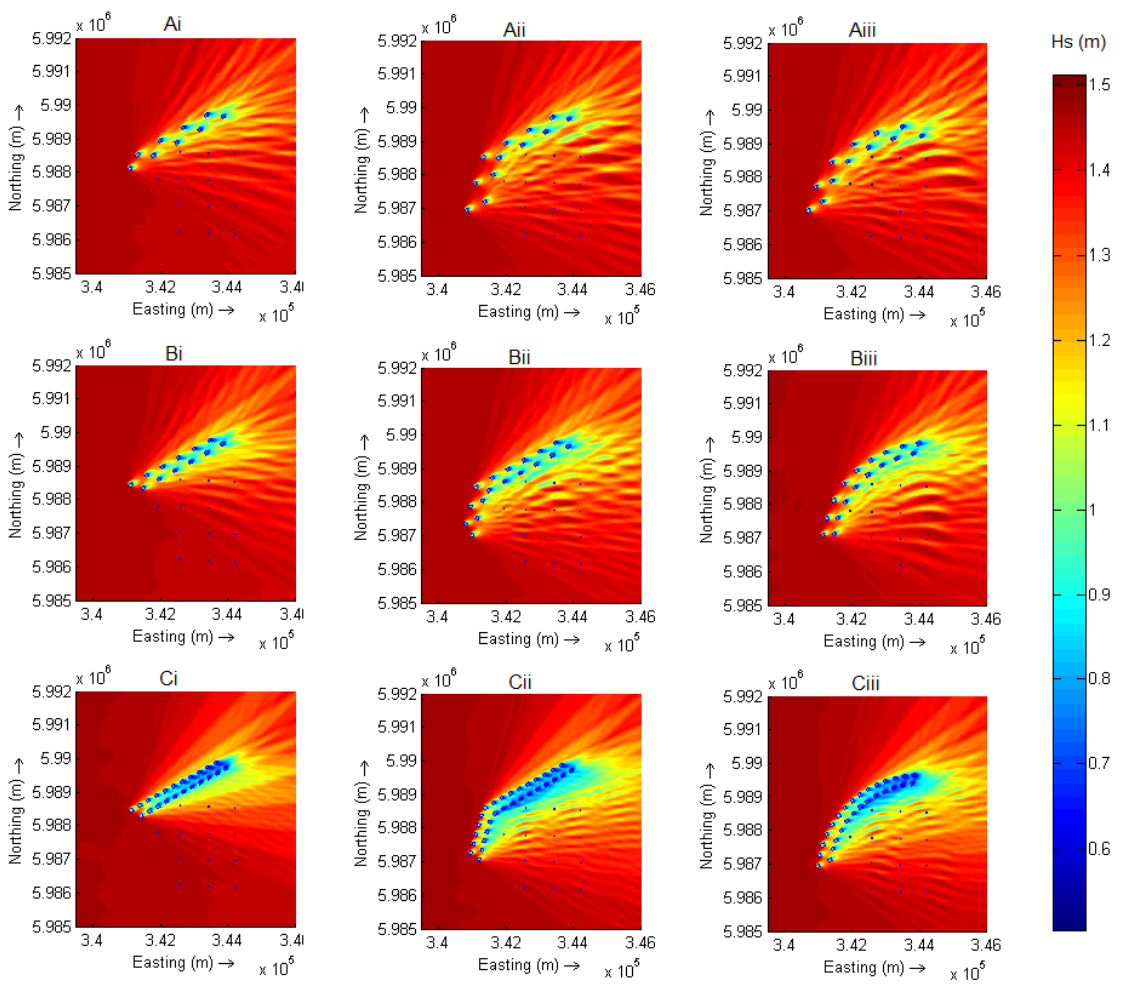

Figure 10. Wave height reduction within the wind farm $(H R F)$ for $H_{s}=1.5 \mathrm{~m}, T_{p}=6.5 \mathrm{~m}$ and $\theta=250^{\circ}$ and 256 configurations $\mathrm{A}_{\mathrm{i}}$ to $\mathrm{C}_{\mathrm{iii}}$. 
Table 8. $H R F(\%)$ values for CS1 $\left(H_{s}=1.5 \mathrm{~m}, T_{p}=6.5 \mathrm{~m}, \theta=330^{\circ}\right)$ and CS2 $\left(H_{s}=1.5 \mathrm{~m}, T_{p}=6.5 \mathrm{~m}, \theta=\right.$ $258250^{\circ}$ ), and configurations $\mathrm{A}_{\mathrm{i}}$ to $\mathrm{C}_{\mathrm{iii}}$.

\begin{tabular}{cccccc}
\hline & & \multicolumn{3}{c}{$H R F(\%)$} \\
\cline { 4 - 6 } Configuration & $N_{W E C s}$ & CS1 & CS2 & $\begin{array}{c}\text { Weighted } \\
\text { average }\end{array}$ \\
\hline \multirow{2}{*}{$\mathrm{A}$} & $\mathrm{A}_{\mathrm{i}}$ & 9 & 12 & 2 & 9 \\
& $\mathrm{~A}_{\mathrm{ii}}$ & 12 & 13 & 6 & 11 \\
& $\mathrm{~A}_{\mathrm{iii}}$ & 12 & 13 & 4 & 11 \\
\hline \multirow{3}{*}{$\mathrm{B}$} & $\mathrm{B}_{\mathrm{i}}$ & 12 & 14 & 4 & 11 \\
& $\mathrm{~B}_{\mathrm{ii}}$ & 17 & 16 & 9 & 14 \\
& $\mathrm{~B}_{\mathrm{iii}}$ & 17 & 16 & 8 & 14 \\
$\mathrm{C}$ & $\mathrm{C}_{\mathrm{i}}$ & 22 & 25 & 5 & 19 \\
& $\mathrm{C}_{\mathrm{ii}}$ & 30 & 27 & 10 & 22 \\
& $\mathrm{C}_{\mathrm{iii}}$ & 28 & 26 & 13 & 22 \\
\hline
\end{tabular}

259 In view of the results (Table 9), $H R F$ is greater in the new layouts proposed than in the basic cases $-C_{i}, C_{i i}$

260 and $\mathrm{C}_{\mathrm{iii}}$. This is due to the better interception not only of southwesterly waves but also of northwesterly, 261 due to the superposition of the shadow effects generated by each individual WEC. The maximum 262 reduction was obtained for the configuration $C_{i i c}(H R F=25 \%)$, i.e. the configuration with two rows at an 263 angle of $45^{\circ}$ and four additional WECs with respect to $\mathrm{C}_{\mathrm{ii}}$. Configuration $\mathrm{C}_{\mathrm{ic}}$ seems to be a good 264 configuration; however, this result is slightly misleading in that it does not reflect the significant 265 differences in wave exposure within the farm - indeed, this configuration leaves the wind turbines in the northwestern sector of the farm exposed to westerly waves.

To sum up, the lower the spacing between devices, the largest the $H R F$ values, and therefore $C_{x}$ configurations generally lead to larger reductions in wave height. Among them, the configurations $\mathrm{C}_{\mathrm{i}}, \mathrm{C}_{\mathrm{ib}}$ and $\mathrm{C}_{\mathrm{ic}}$ should be discarded since they leave part of the wind farm unprotected. On the basis of the results, the configurations $\mathrm{C}_{\mathrm{iic}}$ and $\mathrm{C}_{\mathrm{iiic}}$, with $H R F=25 \%$ and $23 \%$ respectively, were selected for further analysis considering the annual data series from January to December 2013. Moreover, $H R F$ values considering the annual data series were also obtained for $\mathrm{C}_{\mathrm{ii}}$ and $\mathrm{C}_{\mathrm{iii}}$ in order to examine whether adding WECs to the SW of the wind farm is worthwhile. The maximum value of $H R F$ achieved was $18 \%$, which corresponds to the configuration $\mathrm{C}_{\mathrm{iic}}$ (Table 10). However, the arched configuration $\mathrm{C}_{\mathrm{iiic}}$ yielded a similar wave height 
275 reduction, even though this configuration has 2 fewer WECs than $C_{\text {iic }}$, which is interesting for a future analysis in terms of the total cost. Moreover, it was observed that in both cases - configurations with two rows at an angle and in arch - the addition of 4 WECs to the SW increases the reduction by almost two 278 points.

279 Table 9. $H R F(\%)$ values for CS1 $\left(H_{s}=1.5 \mathrm{~m}, T_{p}=6.5 \mathrm{~m}, \theta=330^{\circ}\right)$ and CS2 $\left(H_{s}=1.5 \mathrm{~m}, T_{p}=6.5 \mathrm{~m}, \theta=\right.$ $280250^{\circ}$ ) and configurations $\mathrm{C}_{\mathrm{i}}$ to $\mathrm{C}_{\mathrm{iiic}}$.

\begin{tabular}{|c|c|c|c|c|c|}
\hline \multirow{2}{*}{\multicolumn{2}{|c|}{ Configuration }} & \multirow[b]{2}{*}{$\mathrm{N}_{\text {WECs }}$} & \multicolumn{3}{|c|}{ HRF (\%) } \\
\hline & & & CS1 & \multirow{2}{*}{$\frac{\mathrm{CS} 2}{5}$} & $\begin{array}{c}\text { Weighted } \\
\text { average }\end{array}$ \\
\hline \multirow{3}{*}{ i } & $\mathrm{C}_{\mathrm{i}}$ & 22 & 25 & & 19 \\
\hline & $\mathrm{C}_{\mathrm{ib}}$ & 27 & 28 & 12 & 23 \\
\hline & $\mathrm{C}_{\mathrm{ic}}$ & 31 & 29 & 15 & 25 \\
\hline \multirow{3}{*}{ ii } & $\mathrm{C}_{\mathrm{ii}}$ & 30 & 27 & 10 & 22 \\
\hline & $\mathrm{C}_{\mathrm{iib}}$ & 32 & 29 & 13 & 24 \\
\hline & $\mathrm{C}_{\mathrm{iic}}$ & 34 & 29 & 16 & 25 \\
\hline \multirow{3}{*}{ iii } & $\mathrm{C}_{\mathrm{iii}}$ & 28 & 26 & 13 & 22 \\
\hline & $\mathrm{C}_{\mathrm{iiib}}$ & 30 & 27 & 15 & 23 \\
\hline & $\mathrm{C}_{\mathrm{iiic}}$ & 32 & 27 & 16 & 23 \\
\hline
\end{tabular}

Table 10. HRF (\%) values for the annual serie Data and configurations $\mathrm{C}_{\mathrm{ii}}$ to $\mathrm{C}_{\mathrm{iiic}}$.

\begin{tabular}{crc}
\hline Configuration & $N_{\text {WECs }}$ & HRF (\%) \\
\hline $\mathrm{C}_{\mathrm{ii}}$ & 30 & 16 \\
$\mathrm{C}_{\mathrm{iic}}$ & 34 & 17 \\
$\mathrm{C}_{\mathrm{iii}}$ & 28 & 16 \\
$\mathrm{C}_{\mathrm{iiic}}$ & 32 & 17 \\
\hline
\end{tabular}

283 As for the assessment of the augmented weather windows for O\&M with co-located WECs, the operational limit for workboats is a significant wave height of $1.5 \mathrm{~m}$. Therefore, the total number of hours when $H_{s} \leq 1.5 \mathrm{~m}$ was quantified for the study period (Table 11). In the baseline scenario (a standalone wind farm) the total number of hours when $H_{s} \leq 1.5 \mathrm{~m}(T)$ was $5916 \mathrm{~h}$, which represents $67.5 \%$ of the year. With the co-located layouts analysed, this value was significantly increased (Table 11). According to the results of the $H R F$ assessment, the best scenario was obtained for configuration $\mathrm{C}_{\mathrm{iic}}$, with an increase in the accessibility to the turbines $\left(\triangle T_{O \& M}\right)$ of approximately $20 \%$. The arched configuration $\mathrm{C}_{\mathrm{iiic}}$ shows a very 
290 similar increase with 2 WECs fewer (17.8\%). In both cases, the accessibility was above $82 \%$, which is the

291 reference value to maintain the wind farm availability above 90\% [24].

292 Table 11. $T_{W E C s}$. accesibility and $\Delta T_{O \& M}$ for configurations $\mathrm{C}_{\mathrm{ii}}, \mathrm{C}_{\mathrm{iic}}, \mathrm{C}_{\mathrm{iii}}, \mathrm{C}_{\mathrm{iiic}}$.

\begin{tabular}{cccc}
\hline Configuration & $T_{W E C S}(\mathrm{~h})$ & Accesibility(\%) & $\Delta T_{O \& M}(\%)$ \\
\hline $\mathrm{C}_{\mathrm{ii}}$ & 7074 & 80.8 & 16.4 \\
$\mathrm{C}_{\mathrm{iic}}$ & 7212 & 82.3 & 18.0 \\
$\mathrm{C}_{\mathrm{iii}}$ & 6840 & 78.1 & 13.5 \\
$\mathrm{C}_{\mathrm{iiic}}$ & 7200 & 82.2 & 17.8 \\
\hline
\end{tabular}

293 The best results were obtained for the configurations with smaller spacing between devices and WECs

294 facing not only the main wave direction (W) but also the secondary wave directions (NW and SW), for 295 these provide a similar wave height reduction in the entire wind farm area. Furthermore, it is worth 296 pointing out that, although the greatest level of accessibility to the wind turbines was obtained for the 297 configuration with WEC rows at an angle, the arched configuration achieved a similar value, despite 298 having two WECs less, which could be an interesting aspect for a future study into cost-effectiveness.

\section{3.3. Comparative Study}

300 The proper functioning of the nearshore wave propagation model was validated with wave buoy data. In 301 all cases, a good correlation was observed between the simulated and measured time series, as shown by 302 the values of $R^{2}$ and $R M S E$, always higher than 0.93 and lower than $0.36 \mathrm{~m}$, respectively.

303 As regards the wave height reduction achieved throughout the farm $(H R F)$, it ranged between $13 \%$ and $19 \%$ 304 (Table 12) and was always larger for the layouts with WECs deployed at an angle than for those in arch, 305 although the difference between the results of both configurations was small (between 1 and 2\%). 306 Comparing the results between wind farms (Table 12), the best values were obtained for Bard 1, where a good interception of the incoming waves was achieved for the two layouts of co-located farms (Figure 11). These results were followed very closely by those obtained for Alpha Ventus and Horns Rev 1, whereas 309 the wave height reduction achieved at Lincs was smaller. This was due to three main factors. First, the 310 wind farm layout - this farm has a slightly elongated shape. Second, the wave direction has a greater 
311 variability than in the other case studies, and the farm remained unprotected against waves from secondary

312 directions (Figure 12). For this reason a larger number of WECs would be required on the east side of the

313 farm to achieve better results; however, this would imply an important increase in the ratio between the

314 number of WECs and wind turbines, raising the final cost of the co-located farm. Third, the wave climate

315 in this park, which was milder than in the other farms and, therefore, less wave energy could be extracted

316 by the co-located WECs.

317 Table 12. HRF (\%) values achieved with co-located WECs deployed in angle or in arch based on the 318 annual data series

\begin{tabular}{llll}
\hline Wind farm & Layout & $N_{\text {WECs }}$ & HRF (\%) \\
\hline \multirow{2}{*}{ Alpha Ventus } & in angle & 34 & 18 \\
& in arch & 32 & 17 \\
\hline \multirow{2}{*}{ Bard 1 } & in angle & 79 & 19 \\
& in arch & 79 & 17 \\
\hline \multirow{2}{*}{ Horns Rev 1 } & in angle & 55 & 17 \\
& in arch & 53 & 15 \\
\hline \multirow{2}{*}{ Lincs } & in angle & 81 & 14 \\
& in arch & 80 & 13 \\
\hline
\end{tabular}
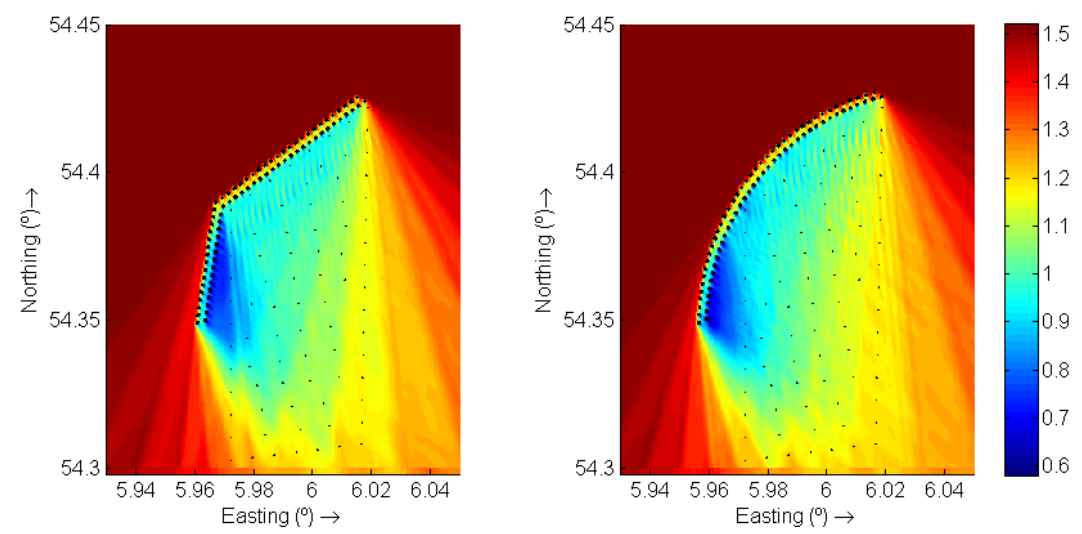

Figure 11. Wave height reduction obtained with co-located WECs at Bard 1 under a sea state with: $H s=$ $1.71 \mathrm{~m}, \mathrm{Tp}=6.09 \mathrm{~s}$ and $\theta=230^{\circ}$. The colour scale represents the significant wave weight, $\mathrm{Hs}(\mathrm{m})$. 

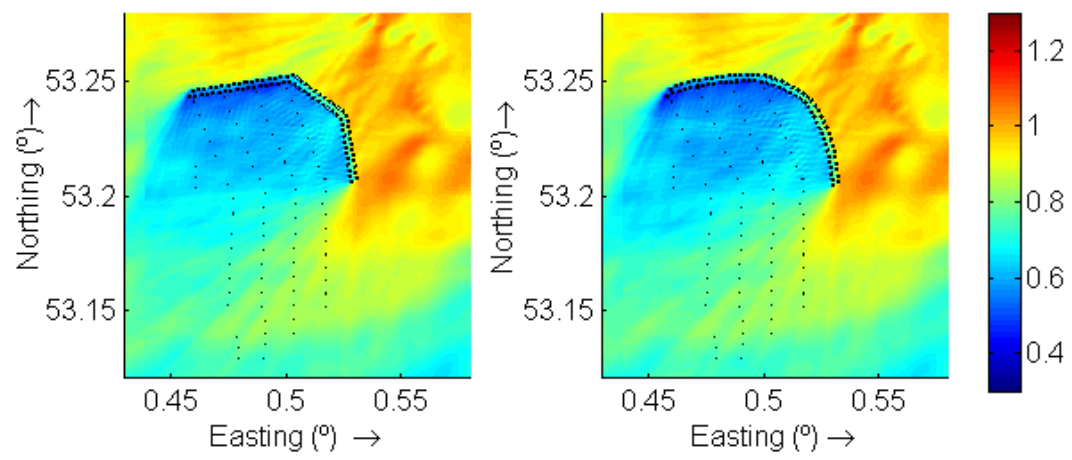

Figure 12. Wave height reduction due to co-located WECs at Lincs under a sea state with: $H s=1.18 \mathrm{~m}$, $T p=6.03 \mathrm{~s}$ and $\theta=60^{\circ}$. The colour scale represents the significant wave weight, $H s(\mathrm{~m})$.

Furthermore, the results of Horns Rev 1 are particularly interesting since they were similar to those of the best scenario, even though the ratio between number of WECs and wind turbines in Horns Rev 1 is much lower than in the other cases - an important consideration for the economic assessment. The explanation lies in the geometry of the wind farms: the layout of Horns Rev 1 is close to a square, whereas Bard 1 or Lincs have a more elongated shape and therefore require more WECs for a similar degree of shelter. Apart from the average wave height reduction in the farm (HFR), it is interesting to analyse the spatial variation in the wave height reduction through its value in different sections $\left(H R A_{j}\right)$, since the best WECs layout should achieve not only high values of HFR but also a fairly homogenous reduction throughout the farm. As may be expected, in all case studies the tendency was for the highest reduction to occur immediately behind the WECs, with $H R A_{j}$ decreasing with increasing distance from the co-located WECs (Figure 13). However, the wave height reduction was significant even as the distance from the WECs increased. As with the wave height reduction for the entire farm, greater values of $H R A_{j}$ were obtained generally for configurations with WECs deployed at an angle rather than in arch. Lincs presented the highest difference between $H R A_{j}$ values in the first and second area of turbines (around 23\%), and was also the case with the smallest difference between the wave height reduction with co-located WECs in angle or in arch. Therefore, it may be concluded that in the case of wind farms with a milder wave climate, like Lincs, wave heights are restored more quickly behind the WEC barrier, and the choice between 
angular or arched layouts for the co-located WECs does not have a significant influence on the

enlargement of the weather windows for O\&M.
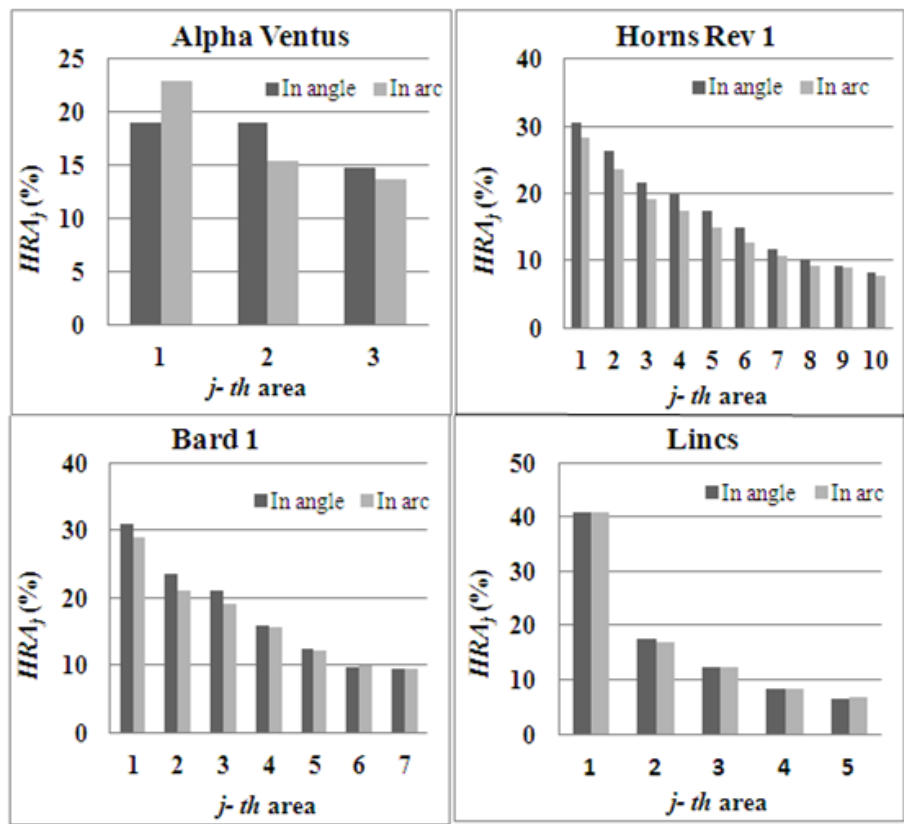

Figure 13. HRAj (\%) values with co-located WECs deployed in angle or in arch based on the annual data series data.

352 As regards the accessibility to the wind turbines, it was below $82 \%$ for all the wind farms analysed (Table

13), which corresponds to availability values below $90 \%$. Nevertheless, an important increase of the

accessibility was achieved by deploying co-located WECs along the periphery of the farm in the four case studies (Table 14). More specifically, the results for Alpha Ventus and Bard 1 were very similar, the accessibility increased $\left(\Delta T_{O \& M}\right)$ by $17-18 \%$, whereas in Horns Rev 1 this increased by $13-15 \%$ and in Lincs by $8 \%$.

Table 13. Accessibility to the wind turbines in the baseline scenario for the annual period analysed.

\begin{tabular}{lc}
\hline Wind farm & Accessibility (\%) \\
\hline Alpha Ventus & 67.5 \\
\hline Bard 1 & 57.0 \\
\hline Horns Rev 1 & 59.9 \\
\hline Lincs & 74.1 \\
\hline
\end{tabular}


361 Table 14 . Accessibility and $\Delta T_{O \& M}$ values for the co-located farms considered.

\begin{tabular}{llcc}
\hline Wind farm & Layout & Accessibility $(\%)$ & $\Delta T_{O \& M}(\%)$ \\
\hline \multirow{2}{*}{ Alpha Ventus } & in angle & 82.3 & 18.0 \\
\cline { 2 - 4 } & in arch & 82.2 & 17.8 \\
\hline \multirow{2}{*}{ Bard 1 } & in angle & 69.7 & 18.2 \\
\cline { 2 - 4 } & in arch & 69.0 & 17.5 \\
\hline \multirow{2}{*}{ Horns Rev 1 } & in angle & 70.9 & 15.6 \\
\cline { 2 - 4 } & in arch & 69.5 & 13.9 \\
\hline \multirow{2}{*}{ Lincs } & in angle & 81.3 & 8.9 \\
\cline { 2 - 4 } & in arch & 81.1 & 8.6 \\
\hline
\end{tabular}

\section{4. Conclusions}

364 The aim of this study was to analyse and compare the wave height reduction achieved with different co365 located farm layouts and find the configuration that improves the shielding effect of the WECs. To 366 achieve this purpose a number of case studies were considered, using real wave conditions and a third367 generation wave model (SWAN). First, an important wave height reduction was achieved in all cases, 368 with significant enlargements of the weather windows for O\&M. In fact, in the case of Alpha Ventus and 369 Lincs, values around 82\% were obtained for the accessibility, which would ensure an availability of the turbines of $90 \%$ or higher. With regard to the influence of the co-located farm layout on the results, the arrays with small spacing between converters achieved the best results of wave height reduction.

372 Moreover, the best results were obtained for co-located wave arrays that face both the prevailing and 373 secondary wave directions, either with WECs deployed in angle or arch. Concerning the influence of the 374 wind farm location, it was found that proximity to land is not a positive factor to implement co-located WECs, since it normally implies lower water depths and a milder sea climate, and consequently there is 376 less available wave energy to be extracted by the WECs. The wind farm layout is another key factor - the 377 largest wave height reduction was achieved for wind farms with square like geometries and smaller spacing between wind turbines, like Horns Rev 1. 
In sum, this work: (i) showed that the weather windows regarding wave height are increased as a result of the presence of the wave farm; and (ii) analysed the main aspects to be taken into account in deploying co381 located WECs for this purpose.

\section{Acknowledgment}

This work was carried out in the framework of the Atlantic Power Cluster project (Atlantic Area Project nr. 2011-1/151, ATLANTICPOWER), funded by the Atlantic Area Operational Transnational Programme as part of the European Regional and Development Fund (ERDF). S. Astariz has been supported by FPU grant 13/03821 of the Spanish Ministry of Education, Culture and Sport. The authors are grateful to: the Bundesamt für Seeschifffahrt und Hydrographie (BSH) of Germany for providing access to the

bathymetric and wave data from the FINO 1, 2 and 3 research platforms; to the UK's Centre for

Environment, Fisheries and Aquaculture Science (CEFAS) for the wave data from the Dowsign buoy; to the Horns Rev wind farm for the resource data of the site; and to the European Marine Observation and Data Network (EMODnet) for the bathymetric data of the North Sea.

\section{References}

[1] S. Astariz and G. Iglesias, "Wave energy vs. Other energy sources: a reassessment of the economics", International Journal of Green Energy. In Press (2014).

[2] C. Pérez-Collazo, D. Greaves, G. Iglesias. "A review of combined wave and offshore wind energy", Renewable and Sustainable Energy Reviews, vol. 42, pp.141-53, 2015.

[3] C. Pérez-Collazo, M.M. Jakobsen, H. Buckland and J. Fernández-Chozas, "Synergies for a wave-wind energy concept". In EWEA, Frankfurt, Germany, 2013.

[4] S. Astariz, C. Perez-Collazo, J. Abanades and G. Iglesias,"Co-located wind-wave farm synergies

(Operation \& Maintenance): A case study", Energy Conversion and Management, vol. 91, pp. 63-75, 2015.

[5] G.J.W. van Bussel and M.B. Zaaijer, "Reliability, Availability and Maintenance aspects of large-scale offshore wind farms, a concepts stud". In Offshore wind energy special topic conference, Brussels, Belgium, 2001.

[6] Wave Hub. Available at: http://www.wavehub.co.uk/about/location-of-wave-hub/ (13/06/2015).

[7] D.L. Millar, H.C.M. Smith and D.E. Reeve, "Modelling analysis of the sensitivity of shoreline change to a wave farm", Ocean Engineering, vol. 34, pp. 884-901, 2007.

[8] J.P. Kenny. "SW Wave Hub- Meteocean design basis". METOC2009. p. 111. 
[9] TUDelft. "Wind farm optimization, Horns Rev: optimization of layout for wake losses in: T.U".

Eindhoven, (Ed.). SET MSc course wind energy2006.

[10] G. Iglesias, H. Fernández, R. Carballo, A. Castro and F. Taveira-Pinto, "The WaveCat@ -

Development of a new Wave Energy Converter World". Renewable Energy Congress 2011, Linkoping, Sweden, 2011.

[11] H. Fernandez, G. Iglesias, R. Carballo, A. Castro, J.A. Fraguela, F. Taveira-Pinto, et al., "The new wave energy converter WaveCat: Concept and laboratory tests", Marine Structures, vol. 29, pp. 58-70, 2012.

[12] G.J. Allan, I. Bryden, P.G. McGregor, T. Stallard, J. Kim Swales, K. Turner, et al., "Concurrent and legacy economic and environmental impacts from establishing a marine energy sector in Scotland", Energy Policy, vol. 36 pp. 2734-2753, 2008.

[13] DOTI GmbH (2011). Alpha Ventus Fact Sheet. Available at: http://www.alphaventus.de/uploads/media/av_Factsheet_en_May_2011.pdf.

[14] C. Beels, P. Troch, J.P. Kofoed, P. Frigaard, J. Vindahl Kringelum, P. Carsten Kromann, et al., "A methodology for production and cost assessment of a farm of wave energy converters", Renewable Energy, vol. 36, pp. 3402-3416, 2012.

[15]http://www.4coffshore.com/windfarms/bard-offshore-1-germany-de23.html (13/06/2015).

[16]http://www.4coffshore.com/windfarms/lincs-united-kingdom-uk13.htm (13/06/2015).

[17] A. Palha, L. Mendes, C.J. Fortes, A. Brito-Melo and A. Sarmento, "The impact of wave energy farms in the shoreline wave climate: Portuguese pilot zone case study using Pelamis energy wave devices",

Renewable Energy, vol. 35, pp. 62-77, 2010.

[18] H.C.M. Smith, C. Pearce and D.L. Millar, "Further analysis of change in nearshore wave climate due to an offshore wave farm: An enhanced case study for the Wave Hub site", Renewable Energy, vol. 40, pp. 51-64, 2012.

[19] J. Abanades, D. Greaves and G. Iglesias, "Wave farm impact on the beach profile: A case study", Coastal Engineering, vol. 86, pp. 36-44, 2014.

[20] S. Ponce de Leon, J.H. Bettencourt, N. Kjerstad, "Simulation of Irregular Waves in an Offshore Wind Farm with a Spectral Wave Model", Continental Shelf Res, vol. 31, p. 17, 2011.

[21] ETSU, "Potential effects of offshore wind developments on coastal processes", ETSU W/35/00596/00/REP. In: P.b.A.a. METOC, (Ed.).

http://www.offshorewindenergy.org/reports/report_002.pdf, 2002.

[22] S. Astariz, C. Perez-Collazo, J. Abanades and G. Iglesias, "Towards the optimal design of a colocated wind-wave farm", Energy, vol. 84, pp. 15-24, 2015.

[23] T. Hayashi, Hattori, M., Kano, T., Shirai and M, "Hydraulic Research on the Closely Spaced Pile Breakwater", Coastal Engineering, vol. 50, p.12, 1966.

[24] G.J.W. van Bussel, W.A.A.M. Bierbooms, "The DOWEC Offshore Reference Windfarm: analysis of transportation for operation and maintenance", Wind engineering, vol. 27, p. 11, 2013. 